\title{
Underutilization of Statin Therapy Among Patients with NAFLD in the USA: Validation with Big Data
}

\author{
Haider Al Taii ${ }^{1}$ - Zaid Yaqoob $^{1} \cdot$ Sadeer G. Al-Kindi $^{1,2}$
}

Received: 23 June 2016/Accepted: 11 July 2016/Published online: 19 July 2016

(C) Springer Science+Business Media New York 2016

\section{To The Editor,}

We read with interest the article by Blais et al. [1] recently published in the Journal. In an analysis of a random sample of 255 patients with Nonalcoholic Fatty Liver Disease (NAFLD) in the Veteran Affairs (VA) hospital system with dyslipidemia, only $152(59.6 \%)$ were on statin therapy. We sought to validate these findings in larger, non-VA hospital systems in the USA. Additionally, because women are greatly underrepresented in the VA cohort $(5 \%)$, we sought to identify gender differences in statin use.

We used Explorys (Cleveland, $\mathrm{OH}$ ), a private clinical registry based on billing codes, electronic medical records, and laboratory results from 26 major healthcare organizations and 360,000 providers covering about 50 million unique lives in the USA [2]. Using International Classification of Diseases version 9 code 571.8, we identified patients with NAFLD (age 18-65 years) and low-density lipoprotein (LDL) levels of $\geq 190 \mathrm{mg} / \mathrm{dL}$ (class I indication for statin therapy in the adult treatment panel guidelines [3]). We excluded patients with AST or ALT $\geq$ three times upper limit of normal.

We identified 9960 patients with NAFLD and LDL $\geq 190 \mathrm{mg} / \mathrm{dL}$ (59\% female, $82 \%$ Caucasians). Diabetes was diagnosed in $44 \%$ of the patients, and $73 \%$ had hypertension. Overall, 7030 (71\%) of the patients had a statin prescription. There was no difference in statin

Sadeer G. Al-Kindi

sadeer.alkindi@uhhospitals.org

1 Department of Medicine, Fairview Hospital, Cleveland Clinic Foundation, University Hospitals Case Medical Center, Case Western Reserve University, Cleveland, OH, USA

2 Harrington Heart and Vascular Institute, 11100 Euclid Ave, Cleveland, OH 44106, USA prescription between males and females $(p=0.86)$. However, African Americans had a higher rate of statin prescription than Caucasians (76 vs. $70 \%, p<0.001$ ).

In summary, our findings of a large non-VA "realworld" cohort of NAFLD with significant LDL elevation showed underutilization of statin in this high-risk population. There seems to be a small racial disparity, but no gender differences were observed in statin utilization. Quality improvement projects should focus on optimization of statin utilization in this patient population.

\section{Compliance with ethical standards}

Conflict of interest None.

\section{References}

1. Blais P, Lin M, Kramer JR, El-Serag HB, Kanwal F. Statins are underutilized in patients with nonalcoholic fatty liver disease and dyslipidemia. Dig Dis Sci. 2016;61:1714-1720.

2. Explorys. Available at: https://www.explorys.com/.

3. Stone NJ, Robinson JG, Lichtenstein AH, et al. 2013 ACC/AHA guideline on the treatment of blood cholesterol to reduce atherosclerotic cardiovascular risk in adults. A report of the American College of Cardiology/American Heart Association Task Force on Practice Guidelines. $J$ Am Coll Cardiol. 2013;63:2889-2934. 